\title{
Difference in prevalence of diabetes and diabetic retinopathy among low-altitude dwellers vs. high-altitude dwellers in North India
}

\author{
Anil Chauhan', Anil Kumar Verma ${ }^{1}$, Deepak Sharma ${ }^{1}$, Lalit Gupta', \\ Dinesh Kumar ${ }^{1}$, Gaurav Sharma ${ }^{1}$, Ashoo Grover ${ }^{2}$ \\ 'Department of Ophthalmology, Dr Rajendra Prasad Government Medical \\ College, Kangra, India; ${ }^{2}$ Indian Council of Medical Research, New Delhi, India
}

\begin{abstract}
Background: Type-2 diabetes mellitus (DM) is one of the leading lifestyle-related chronic disease as its prevalence is expected to rise up to $24.0 \%$ in the world by 2025 , which was only $6.3 \%$ in year 2003.

Objective: To understand the high-altitude and low-altitude differentials for DM and diabetic retinopathy (DR) prevalence in a sub-Himalayan state of North India.

Methods: The study was carried out in the Shahpur block of Kangra district (altitude 2,404 feet) and the Spiti block of Lahaul and Spiti district (altitude 12,500 feet) of Himachal Pradesh.

Results: Among diabetics, the prevalence of DR was observed to be high (18.1\%) in low landers and low (5.0\%) in high landers. DM was more of a problem among low landers with a prevalence of $12.3 \%$ when compared to high landers (7.2\%). Overall, the odd ratio of DR was twice as high (2.2; 95\% confidence interval [Cl]: 1.1-2.3) among patients with an unsatisfactory level of $\mathrm{HbA1C}(>8.0 \%)$ adjusted for gender, age group, smoking status and hypertension.

Conclusion: Differential did exist, as DM and DR were significantly lower in high-altitude areas when compared to low-altitude areas.
\end{abstract}

Keywords: diabetes mellitus, diabetic retinopathy, high landers and low landers, retinopathy

\section{Introduction}

Type-2 diabetes mellitus (DM) is one of the leading lifestyle-related chronic diseases as its prevalence is expected to increase up to $24.0 \%$ globally by 2025 when compared to $6.3 \%$ in the year 2003: most in East Asia and Pacific and least in sub-Saharan Africa region. ${ }^{1}$ Worldwide, DM causes estimated 9,59,000 deaths and 19,96,000 disability-adjusted life years. ${ }^{1}$ DM-associated mortality and morbidity is due to micro-vascular

Correspondence: Dr Anil Chauhan, Professor, Department of Ophthalmology, Dr Rajendra Prasad Government Medical College, Kangra at Tanda, Himachal Pradesh 176001, India.

E-mail: dr.a.chauhan@gmail.com 
(retinopathy, nephropathy and kidney failure) and macro-vascular (coronary heart disease, stroke, peripheral vascular disease and lower-extremity amputation) complications. Diabetic retinopathy (DR) is one of the serious complications, and if detected late can cause severe and irreversible loss of vision in an affected eye.

Lifestyle factors like physical inactivity, unhealthy diet, tobacco smoking and alcohol consumption are observed to be responsible for the onset of chronic diseases, including DM. Earlier considered only to be the disease of urban, chronic conditions have now been reported from rural areas of the country. ${ }^{1-4}$ Evidence from population living in lower-altitude areas are available, but it is scanty for people living in high altitude. Therefore, present study was planned to assess the prevalence of DM and DR among low landers and high landers in a sub-Himalayan state of North India.

\section{Methodology}

This study was carried out in Shahpur block (low-altitude belt, 2,404 feet) of Kangra district and Spiti block (high-altitude belt, 12,500 feet) of Lahaul and Spiti district of Himachal Pradesh. This high-altitude belt is also the tribal belt which is a state notified area, and its population resides at an average of 12,500 feet from the mean sea level (MSL), whereas low-altitude areas spread over an average of 2,404 feet from the MSL. Population of tribal area residing in tough environmental conditions, as the area remained isolated from the rest of state due to heavy snowfall for 6 months (November to April), and inter-village connectivity remains disrupted for 3 months (December to February) every year. People living in the tribal area carry out agriculture, horticulture and cattle farming for livelihood. In order to estimate the prevalence of DM, the sample size of 3,445 in each area was calculated assuming $10.0 \%$ prevalence, design effect of $4,80.0 \%$ study power and $95.0 \%$ level of significance. The villages were considered as the unit (cluster) of the study and 20 clusters with probability proportion to size were selected from the list of villages of each area. Structured interview schedule was administered by the trained field staff along with anthropometry and assessment for DM. It was done in the selected village across its entire households by door-to-door survey among individuals more than 20 years of age. Information on smoking, hypertension, duration of diabetes and family history of DM was collected along with the assessment for fasting blood sugar (FBG) with a standardized glucometer. Individuals with known case of DM and with FBG of $\geq 126 \mathrm{mg} / \mathrm{dl}$ were labelled as diabetics, and all of them were then assessed for glycosylated haemoglobin ( $\mathrm{HbA1c}$ ) with Nyco Card reader. All diabetics were assessed by an ophthalmologist for DR with the Fundus camera (VisuCam-500) along with measurement of intraocular pressure 
(IOP) with the use of the tonometer. The informed consent was sought from the participants during the interview, anthropometry, blood sample collection and retinal assessment. The study was funded by the Indian Council of Medical Research, New Delhi, India, and approved by the Institute Ethics Committee. Data was entered and analyzed using the Epi Info software, Centre for Disease Control, Atlanta.

\section{Results}

Totally 2,204 individuals in the high-altitude area and 3,404 individuals in the low-altitude area were interviewed and assessed for DM. The prevalence of DM was found to be $7.2 \%$ among the high landers and $12.3 \%$ among the low landers with the mean FBG level of $101.1 \mathrm{mg} / \mathrm{dl}$ and $136.6 \mathrm{mg} / \mathrm{dl}$ in the high landers and low landers, respectively. The levels for the mean FBG was $104.9 \mathrm{mg} / \mathrm{dl}$ and $158.1 \mathrm{mg} / \mathrm{dl}$ in already known cases of DM. The prevalence of DR in the screened population was $0.3 \%$ among high landers and $2.2 \%$ among low landers. DR was prevalent in $5 \%$ and $18.1 \%$ of diabetic patients in the high-altitude and low-altitude areas, respectively (Table 1 ).

Looking for the differential variables, it was observed that the mean age of the screened population was 50.1 years in high landers when compared to 56.3 years in the low landers. The average age of diabetics in high landers was low (51.9 years) when compared to low landers (57.2 years). The age group distribution observed that more than half of the screened and about half of diabetic population were of 20 to 50 years of age in high-altitude area, indicating relatively more representation of younger population.

A gender differential was observed as significantly more proportion of males were screened $(41.1 \%$ vs. $25.3 \%)$ and found diabetic $(44.9 \%$ vs. $33.2 \%)$ in the high-altitude area when compared with the low-altitude area.

The prevalence of known cases of DM among all diabetics was $7.9 \%$ among the high landers and $84.4 \%$ among the low lander. Among known cases of DM, the regular intake of medicine was reported in $21.7 \%$ and $90.3 \%$ patients of the high-altitude and low-altitude areas, respectively (Table 1 ).

Among diabetics who reported history of regular intake of anti-diabetic drugs, the significant difference in the mean level of $\mathrm{HbA1c}$ was found to be 9.3 (SD \pm $2.5)$ and $7.7(S D \pm 1.7)(p<0.0011)$ among high landers and low landers, respectively. The prevalence of unsatisfactory levels of $\mathrm{HbA1c}(>8.0 \%)$ was observed to be $80.0 \%$ among high landers and $40.0 \%$ among low landers $(p=0.05)$ (data not shown). But when assessed for all diabetics (old and new), it was observed that the mean $\mathrm{HbA} 1 \mathrm{c}$ was lower among high landers (6.3\% vs. $7.7 \%)$ with relatively low prevalence for unsatisfactory levels of $\mathrm{HbA} 1 \mathrm{c}(\geq 8.0 \%)$ among high landers (11.3\% vs. $41.1 \%)$ when compared to the low landers (Table 2 ). 
Low- vs. high-altitude prevalence for DM and DR

Table 1. Distribution of observed variables among screened population and diabetics in high-altitude and low-altitude areas of Himachal Pradesh, India

\begin{tabular}{|c|c|c|c|c|c|c|}
\hline \multirow[t]{2}{*}{ Variable } & \multicolumn{2}{|c|}{ Screened population } & \multirow[t]{2}{*}{ P-value } & \multicolumn{2}{|c|}{ Diabetics } & \multirow[t]{2}{*}{ P-value } \\
\hline & $\begin{array}{l}\text { High } \\
\text { landers } \\
(2,204)\end{array}$ & $\begin{array}{l}\text { Low } \\
\text { landers } \\
(3,404)\end{array}$ & & $\begin{array}{l}\text { High } \\
\text { landers } \\
\text { (159) }\end{array}$ & $\begin{array}{l}\text { Low } \\
\text { landers } \\
\text { (418) }\end{array}$ & \\
\hline $\begin{array}{l}\text { Mean FBS } \\
(\mathrm{mg} / \mathrm{dl}) \\
( \pm \mathrm{SD})\end{array}$ & $101.1(28.3)$ & $136.6(65.9)$ & $<0.001$ & $\begin{array}{l}104.9 \\
(32.0)\end{array}$ & $158.1(51.5)$ & $<.001$ \\
\hline $\begin{array}{l}\text { Mean age } \\
\text { (years) } \\
( \pm S D)\end{array}$ & $50.1(10.9)$ & $56.3(11.3)$ & $<0.001$ & $\begin{array}{l}51.9 \\
(10.0)\end{array}$ & $57.2(9.1)$ & $<0.001$ \\
\hline \multicolumn{7}{|l|}{$\begin{array}{l}\text { Age group } \\
\text { (years) (\%) }\end{array}$} \\
\hline $20-40$ & 26.5 & 6.9 & $<0.001$ & 20.2 & 3.1 & $<0.001$ \\
\hline $41-50$ & 35.9 & 32.3 & $<0.001$ & 29.1 & 23.2 & 0.07 \\
\hline $51-60$ & 20.2 & 28.8 & $<0.001$ & 30.1 & 43.7 & $<0.001$ \\
\hline $61-70$ & 11.5 & 21.7 & $<0.001$ & 16.4 & 23.4 & 0.02 \\
\hline$>70$ & 5.9 & 10.2 & $<0.001$ & 4.1 & 6.7 & 0.14 \\
\hline Male (\%) & 41.1 & 25.3 & $<0.001$ & 44.9 & 33.2 & $<0.001$ \\
\hline $\begin{array}{l}\text { Known case } \\
\text { of DM (\%) }\end{array}$ & & & & 7.9 & 84.4 & $<0.001$ \\
\hline $\begin{array}{l}\text { Family } \\
\text { history of } \\
\text { DM (\%) }\end{array}$ & & & & 2.0 & 21.2 & $<0.001$ \\
\hline $\begin{array}{l}\text { Known case } \\
\text { of hyperten- } \\
\text { sion (\%) }\end{array}$ & & & & 6.5 & 39.6 & $<0.001$ \\
\hline $\begin{array}{l}\text { Taking } \\
\text { treatment } \\
\text { for DM (\%) }\end{array}$ & & & & 21.7 & 90.3 & $<0.001$ \\
\hline $\begin{array}{l}\text { Duration of } \\
\text { smoking }\end{array}$ & & & & & & \\
\hline
\end{tabular}


Chauhan, et al.

\begin{tabular}{|c|c|c|c|c|c|c|}
\hline \multirow[t]{2}{*}{ Variable } & \multicolumn{2}{|c|}{ Screened population } & \multirow[t]{2}{*}{ P-value } & \multicolumn{2}{|c|}{ Diabetics } & \multirow[t]{2}{*}{ P-value } \\
\hline & $\begin{array}{l}\text { High } \\
\text { landers } \\
(2,204)\end{array}$ & $\begin{array}{l}\text { Low } \\
\text { landers } \\
(3,404)\end{array}$ & & $\begin{array}{l}\text { High } \\
\text { landers } \\
\text { (159) }\end{array}$ & $\begin{array}{l}\text { Low } \\
\text { landers } \\
(418)\end{array}$ & \\
\hline$<1$ year & 4.0 & 2.0 & $<0.001^{a}$ & 2.9 & 0.0 & NA \\
\hline $1-5$ year & 10.3 & 7.0 & 0.13 & 2.9 & 2.0 & 0.01 \\
\hline 5-10 year & 14.3 & 2.6 & $<0.001$ & 20.6 & 5.9 & 0.08 \\
\hline$>10$ year & 71.3 & 95.5 & $<0.001$ & 73.5 & 92.2 & 0.01 \\
\hline \multicolumn{7}{|l|}{$\begin{array}{l}\text { Cigarettes } \\
\text { per day }\end{array}$} \\
\hline$<5$ & 17.8 & 21.5 & 0.28 & 11.8 & 27.5 & 0.08 \\
\hline $5-10$ & 13.0 & 19.4 & 0.04 & 8.8 & 13.7 & $0.73^{a}$ \\
\hline$>10$ & 68.9 & 58.8 & 0.01 & 79.4 & 58.8 & 0.04 \\
\hline $\begin{array}{l}\text { Ever tested } \\
\text { for lipids (\%) }\end{array}$ & 0.5 & 16.6 & & & & \\
\hline $\begin{array}{l}\text { Mean blood } \\
\text { pressure }\end{array}$ & $127 / 34$ & $128 / 78$ & $<0.001$ & $126 / 88$ & $134 / 88$ & $<0.001$ \\
\hline \multicolumn{7}{|l|}{$\begin{array}{l}\text { hyperten- } \\
\text { sion stage } \\
(\mathrm{mmHg})\end{array}$} \\
\hline $\begin{array}{l}\text { Normal } \\
(<120 \text { and } \\
<80)\end{array}$ & 42.8 & 41.4 & $<0.001$ & 33.2 & 39.1 & 0.13 \\
\hline $\begin{array}{l}\text { Pre }(120-139 \\
\text { or } 80-89)\end{array}$ & 37.3 & 39.7 & $<0.001$ & 19.9 & 20.3 & 0.87 \\
\hline $\begin{array}{l}\text { Stage- } 1 \\
(140-159 \text { or } \\
90-99)\end{array}$ & 12.3 & 16.9 & $<0.001$ & 28.4 & 31.3 & 0.42 \\
\hline $\begin{array}{l}\text { Stage- } 2 \\
(\geq 160 \text { or } \\
\geq 100)\end{array}$ & 7.6 & 2.9 & $<0.001$ & 18.5 & 9.3 & $<0.001$ \\
\hline
\end{tabular}

aYates' corrected Chi-square 
Low- vs. high-altitude prevalence for DM and DR

Table 2. Distribution of fasting blood sugar, $\mathrm{HbA} 1 \mathrm{c}$ and IOP detected in diabetics and individuals with DR in high-altitude and low-altitude areas of Himachal Pradesh, India

\begin{tabular}{|l|l|l|l|l|l|l|}
\hline \multirow{2}{*}{ Variable } & \multicolumn{2}{|l|}{ Diabetics } & P-value & \multicolumn{2}{l|}{ Diabetics with DR } & P-value \\
\cline { 2 - 7 } & $\begin{array}{l}\text { High } \\
\text { landers } \\
(\mathbf{1 5 9 )}\end{array}$ & $\begin{array}{l}\text { Low } \\
\text { landers } \\
\mathbf{( 4 1 8 )}\end{array}$ & $\begin{array}{l}\text { High } \\
\text { landers } \\
\mathbf{( 8 )}\end{array}$ & $\begin{array}{l}\text { Low } \\
\text { landers } \\
\mathbf{( 7 6 )}\end{array}$ & \\
\hline $\begin{array}{l}\text { Mean FBS } \\
(\mathrm{mg} / \mathrm{dl})( \pm \text { SD) }\end{array}$ & $\begin{array}{l}104.9 \\
(32.0)\end{array}$ & $\begin{array}{l}158.1 \\
(51.5)\end{array}$ & $<0.001$ & $\begin{array}{l}146.8 \\
(34.4)\end{array}$ & $\begin{array}{l}185.6 \\
(42.4)\end{array}$ & 0.12 \\
\hline $\begin{array}{l}\text { HbA1C (\%) } \\
( \pm \text { SD) }\end{array}$ & $6.3(1.5)$ & $7.7(1.7)$ & $<0.001$ & $8.1(2.0)$ & $8.3(1.7)$ & 0.82 \\
\hline $\begin{array}{l}\text { IOP right } \\
( \pm \text { SD), mmHg }\end{array}$ & $15.8(4.1)$ & $15.3(4.3)$ & 0.18 & $17.8(4.8)$ & $15.2(4.1)$ & 0.18 \\
\hline $\begin{array}{l}\text { IOP left ( } \pm \text { SD), } \\
\text { mmHg }\end{array}$ & $15.4(3.9)$ & $15.5(4.5)$ & 0.59 & $17.1(3.0)$ & $15.7(4.6)$ & 0.26 \\
\hline $\begin{array}{l}\text { High HbA1c } \\
(>8.0 \%)\end{array}$ & 11.3 & 41.1 & $<0.001$ & 66.7 & 62.2 & 0.82 \\
\hline $\begin{array}{l}\text { Hypertension } \\
\text { (Stage-1 and } \\
\text { Stage-2) (\%) }\end{array}$ & 48.6 & 40.4 & 0.95 & 37.5 & 47.4 & 0.85 \\
\hline
\end{tabular}

Among all screened for DM, an assessment for hypertension was performed, finding that the, prevalence of pre-hypertension and stage- 1 hypertension was significantly high among low landers, whereas stage- 2 hypertension was found to be high among high landers. Among diabetics, a similar but insignificant differential, was observed (Table 1).

Among high landers, the prevalence of smoking was $8.5 \%$ when compared to $11.8 \%$ among low landers $(p<0.001)$ with a smoking history for more than 10 years in about $71.3 \%$ of high landers and $95.5 \%$ of low landers $(p<0.001)$ (Table 1$)$. Statistical insignificant difference was observed for IOP in both eyes (right: 15.8 vs. 15.3; left: 15.4 vs.15.5) between both areas (Table 1).

As the prevalence of DR was observed to be significantly high among low landers when compared to high landers and the number of DR cases was less in high-altitude area, so a statistically insignificant difference was observed for mean FBS, HbA1c, IOP and individuals with high HbA1c when compared to the low-altitude area (Table 2). Looking for the potential variables for the difference, it was observed that a significant odds ratio (OR) was observed for unsatisfactory 
HbA1c levels among diabetics with OR of 19.8 (95\% [confidence interval] Cl: 3.3-118.2) in high altitude and 2.8 (95\% Cl: 1.7-4.8) in the low altitude. It was insignificant for gender, age group, smoking and hypertension. The wide $\mathrm{Cl}$ was observed in high-altitude area because of relatively fewer number of DR cases (8). Therefore, combining all the cases of DR of both areas for assessment we observed that the OR of DR was significantly high among diabetics with high HbA1c, 4.3 (95\% $\mathrm{Cl}$ : 2.6-7.0) and individuals of 61 to 70 years of age, 1.8 (95\% Cl: 1.1-3.1). Looking for OR across the age group, an insignificant increasing risk from low to high age group was observed. Adjusting for factors like gender, age group, long duration of DM (high $\mathrm{HbA1c}$ ), smoking and hypertension, it was found that the high $\mathrm{HbA} 1 \mathrm{c}$ was associated with DR with an OR of 2.2 (95\% Cl: 1.2-2.7). It indicates that DR was approximately twice as high among diabetics with long duration of uncontrolled DM (Table 3). All the observed cases of DR were non-proliferative type and not even a single case of proliferative DR was observed in the present study. The most common observation for non-proliferative DR (NPDR) were haemorrhages,

Table 3. Unadjusted and adjusted risk assessment for DR in high-altitude and low-altitude areas of Himachal Pradesh, India

\begin{tabular}{|l|l|l|l|l|}
\hline Variable & High landers (8) & Low landers (76) & \multicolumn{1}{l|}{ Both (84) } \\
\hline Male & OR (95\% CI) & OR (95\% CI) & OR (95\% CI) & OR (95\% CI) \\
\hline $\begin{array}{l}\text { Age group in } \\
\text { years (\%) }\end{array}$ & $3.8(0.7-19.2)$ & $1.3(0.7-2.1)$ & $1.1(0.7-1.8)$ & $0.9(0.5-1.6)$ \\
\hline $20-40$ & $0.3(0.0-4.6)$ & $1.3(0.3-5.0)$ & & \\
\hline $41-50$ & $1.4(0.3-6.3)$ & $0.3(0.1-0.6)$ & $0.3(0.1-0.7)$ & $1.6(0.4-6.6)$ \\
\hline $51-60$ & $0.7(0.1-3.8)$ & $1.1(0.7-1.8)$ & $1.3(0.8-2.0)$ & $0.7(0.2-2.6)$ \\
\hline $61-70$ & $0.7(0.0-5.9)$ & $1.8(1.0-3.1)$ & $1.8(1.1-3.1)$ & $0.3(0.0-1.3)$ \\
\hline$>70$ & $3.5(0.4-31.3)$ & $1.2(0.5-3.1)$ & $1.6(0.7-3.8)$ & $0.3(0.0-1.6)$ \\
\hline High HbA1c & $19.8(3.3-118.2)$ & $2.8(1.7-4.8)$ & $4.3(2.6-7.0)$ & $2.2(1.1-2.7)$ \\
\hline Smoker & $1.2(0.1-10.1)$ & $1.1(0.5-2.3)$ & $1.1(0.6-2.3)$ & $1.0(0.4-2.3)$ \\
\hline $\begin{array}{l}\text { Hyperten- } \\
\text { sion (Stage-1 } \\
\text { \& Stage-2) }\end{array}$ & $0.6(0.1-2.8)$ & $1.4(0.8-2.3)$ & $1.1(0.7-1.8)$ & $0.7(0.4-1.1)$ \\
\hline
\end{tabular}


microaneurysms and hard exudates. It was followed with fewer frequent findings of haze, torturous vessels, cotton wool spots and optic disc changes.

\section{Discussion}

DR is the most important cause of irreversible loss of vision. India is considered as diabetic capital of the World. Among diabetics, studies observed the prevalence of DR as $18 \%\left(\right.$ CURES) ${ }^{5}$ and $19 \%$ (APEDS), ${ }^{6} 10.0 \%{ }^{7}$ and $21.6 \% .{ }^{8}$ Current study observed that among diabetics, the prevalence of DR was $18.1 \%$ in low-altitude areas and $5 \%$ in high-altitude areas. It was of NPDR in nature with significant differential distribution in studied areas. Among screened individuals, it was $2.2 \%$ among low landers and $0.3 \%$ among high landers. In general population of rural India, the prevalence of DR was observed to be $0.6 \%, 1.2 \%, 1.7 \%$, which is quite similar to the present study. ${ }^{8-10}$ However, in evidence from rural Bangladesh, DR prevalence was $5.4 \%$ in its studied participants. ${ }^{11}$ As in the current study, NPDR was the common form in the rural area of Andhra Pradesh (96.4\%). ${ }^{11}$ DR is dependent on the duration of disease and its treatment, which is an important factor related to DM. The current study observed that the OR of DR was twice as high (2.2; 95\% Cl: 1.1-2.3) among patients with an unsatisfactory level of $\mathrm{HbA1c}(>8.0 \%)$ adjusted for gender, age group, smoking status and hypertension. As the biological plausibility, the long duration of DM is certainly the risk factor for DR in both the areas.

DM affects people of all ages and races with increasing prevalence worldwide. In certain regions, successive growth and development leads to associated lifestyle changes exemplified by the reduction of physical activity and increased consumption of high-energy processed foods. ${ }^{12-14} \mathrm{DM}$ prevalence in India ranged from 5.9\% to $12.1 \%$ (North: $8.6 \%-11.6 \%$; South: $13.5 \%-19.5 \%$ ). ${ }^{15,16}$ High prevalence of DM was observed both in urban and rural India (about 2.0\%-10.0\%), ${ }_{1}^{16}$ whereas a systematic review for DM in tribal populations of India observed a ranging prevalence from $0.7 \%$ to $10.0 \%$, with a final estimate of $5.9 \% .{ }^{17}$ The present study tends to understand the pattern of DM and DR as its complication among low landers and high landers. In the high-altitude area with limited availability and accessibility of health care resources, different lifestyle and poor network connectivity, an assumption for low risk for DM and DR was made in the current study. It was observed that the prevalence of DM was statistically high among low landers (12.3\%) when compared to high landers (7.2\%) $(p<0.001)$ with the high mean level of FBG among low landers $(136.6 \mathrm{mg} / \mathrm{dl})$ than high landers $(101.1 \mathrm{mg} / \mathrm{dl})$ areas. In the present study, about $60.0 \%$ among high landers and $40.0 \%$ among low landers were observed to be below 50 years of age, reflecting more of population with young age in high-altitude area when compared to low-altitude area. Among diabetics, about half of patients among high landers and about a quarter among low landers were below 50 years of age. Such type of supportive evidence was observed where about more than half of DM cases were 
less than 50 years of age. ${ }^{18}$ The high-altitude area (tribal area) in the current study was observed to have less prevalence for DM, which is in the observed range of evidence across the country. It may not be actually less but could be a marker for early appearance of chronic diseases in the tribal area.

Smoking increases the risk for DM and associated macro- and micro-vascular complications. ${ }^{19,20}$ Smoking was found to cause substantial changes in insulin sensitivity among patients with non-insulin DM. A meta-analysis showed the prevalence of smoking was high among diabetic patients when compared to normal subjects. ${ }^{21}$ Local evidence from a study conducted in the same state but in a different study area, observed that the prevalence of smoking among diabetics was about $10.0 \%$ in the urban and $4.0 \%$ in the tribal population. ${ }^{22}$ The current study observed that among screened individuals for DM, there was low prevalence of smoking (8.5\%) among high landers when compared to low landers $(11.8 \%)(p<$ 0.001 ), but it was observed almost similar (about 10.0\%-12.0\%) among diabetics in both areas. However, in the low-altitude areas, significantly more screened individuals and diabetics were observed with smoking duration of more than 10 years and consumption of more than 10 cigarettes per day.

Hypertension is a common chronic morbidity associated with DM. ${ }^{23}$ In India, the overall prevalence of hypertension is about $40.0 \%$, more in urban (63.2\%) than in rural (36.8\%) areas and reportedly varies from $20.0 \%$ to $40.0 \%$ in urban and from $12.0 \%$ to $17.0 \%$ in rural India. ${ }^{23}$ Hypertension and DM were observed as co-morbid conditions in a hospital-based study, as in diabetics hypertension prevalence was $60.2 \%, 76.5 \%$, and $85.8 \%$ at blood pressure thresholds of $140 / 90,130 / 85$, and $130 / 80 \mathrm{mmHg}$, respectively. ${ }^{24}$ Descriptive evidence from 10 states in India observed co-existence of DM and hypertension in $20.6 \%$ patients. ${ }^{25}$ Another study from the same study area observed the prevalence of DM as $10.4 \%$ in stage- 1 and $16.9 \%$ in stage- 2 hypertension. ${ }^{22}$ The current study observed that among all screened, hypertension was more prevalent among low landers: high prevalence of stage-1 hypertension among high landers and stage-2 hypertension among low landers. Among diabetics, the prevalence of stage- 1 hypertension was found to be high in both areas, but stage- 2 hypertension was significantly high in the high-altitude area. Overall, about $20.0 \%$ of the screened individuals were hypertensive, which is quite similar to study from central India that found hypertension in $19.4 \%$ of the population, but high when compared to $14.5 \%$ in the rural area of South India.

Surveys in developing countries suggest an early increase in the risks for chronic diseases like DM and hypertension. ${ }^{26}$ The current study observed that there was high prevalence of hypertension, DM and DR among low landers in comparison to high landers, and being in the low-altitude area the OR for DM, hypertension and DR was twice as high than that of the high-altitude area. Evidence from Africa, China and the Pacific islands also documents that the risk-factor level increases when 
people migrate to more urbanized settings. ${ }^{21-25}$ In the present study, the degree of urbanization was not studied, but subjective, not objective, assessment of both the areas showed less urbanization in the high-altitude area when compared to the low-altitude area, which could be the reason for the observed differentials. The high-altitude area remains disconnected from the rest of the state in absence of rail, road and air transport, so, in itself it can be seen as a justification for the complete absence of urbanization. For the high-altitude area, though there was low prevalence of DR and relatively less prevalence for DM and HTN, the effect of urbanization in the coming times cannot be underestimated. So, it becomes important to establish an effective surveillance system to track the lifestyle changes within the community and measures to reduce the impact of urbanization.

There are limitations to the study, as the extent of urbanization was not studied objectively, and inferences drawn in the present evidence are based on the cross-sectional study. However, an effort was made to draw sufficient sample size in both areas to meet statistical assumption, although logistic regression was used as a multivariate statistical test which is robust to violation of assumptions. A far lower number of DR cases limits the statistical analysis, but there is sufficient evidence in favour of early onset of DM among high landers for regular screening and lifestyle interventions.

\section{Acknowledgement}

We express our sincere thanks to the Indian Council of Medical Research, New Delhi, India, for providing the financial assistance.

\section{References}

1. Venkat Narayan KM, Zhang P, Kanaya AM, et al. Diabetes: the pandemic and potential solutions. In: Jamison DT, Breman JG, Measham AR, et al. (Eds). Disease Control Priorities in Developing Countries. 2nd ed. New York. USA. Oxford University Press; 2006.

2. Mathers CD, Stein D, Ma Fat C, et al. Global Burden of Disease 2000: Version 2 Methods and Results. Global Programme on Evidence for Health Policy Discussion Paper Series. Geneva: World Health Organization.

3. Mohan V, Mathur P, Deepa R, et al. Urban rural differences in prevalence of self-reported diabetes in India-The WHO-ICMR Indian NCD risk factor surveillance. Diab Res Clin Pract. 2008;10:1016-1018.

4. Patel RB, Burke TF. Urbanization-an emerging humanitarian disaster. N Engl J Med. 2009 Aug 20;361(8):741-743.

5. Rema M, Premkumar S, Anitha B, Deepa R, Pradeepa R, Mohan V. Prevalence of diabetic retinopathy in urban India: the Chennai Urban Rural Epidemiology Study (CURES) eye study. I. Invest Ophthalmol Vis Sci. 2005;46(7):2328-2333.

6. Leal C, Admetlla J, Viscor G, Ricart A. Diabetic retinopathy at high altitude. High Alt Med Biol. 2008;9(1):24-27.

7. Raman R, Ganesan S, Pal SS, Kulothungan V, Sharma T. Prevalence and risk factors for diabetic retinopathy in rural India. Sankara Nethralaya Diabetic Retinopathy Epidemiology and Molecular Genetic Study III (SN-DREAMS III), report no 2. BMJ Open Diabetes Res Care. 2014;2(1):e000005. eCollection 2014. 
8. Akhter A, Fatema K, Ahmed SF, Afroz A, Ali L, Hussain A. Prevalence and associated risk indicators of retinopathy in a rural Bangladeshi population with and without diabetes. Ophthalmic Epidemiol. 2013;20(4):220-227.

9. Krishnaiah S, Das T, Nirmalan PK, et al. Risk factors for diabetic retinopathy: findings from The Andhra Pradesh Eye Disease Study. Clin Ophthalmol. 2007;1(4):475-482.

10. Namperumalsamy P, Kim R, Vignesh TP, et al. Prevalence and risk factors for diabetic retinopathy: a population-based assessment from Theni district, south India. Postgrad Med J. 2009;85(1010):643-648.

11. Dandona L, Dandona R, Naduvilath TJ, McCarty CA, Rao GN. Population based assessment of diabetic retinopathy in an urban population in southern India. $\mathrm{Br} \mathrm{J}$ Ophthalmol. 1999;83(8):937-940.

12. Allender S, Foster C, Hutchinson L, Arambepola C. Quantification of urbanization in relation to chronic diseases in developing countries: a systematic review. J Urban Health. 2008;85:938-951.

13. Klein R, Sharrett AR, Klein BE, et al. The association of atherosclerosis, vascular risk factors, and retinopathy in adults with diabetes: the atherosclerosis risk in communities study. Ophthalmology. 2002;109(7):1225-1234.

14. Zhang X, Saaddine JB, Chou CF, et al. Prevalence of diabetic retinopathy in the United States, 2005-2008. JAMA. 2010;304(6):649-656.

15. Ramachandran A, Snehalatha C. Current scenario of diabetes in India. J Diabetes. 2009;1(1):18-28.

16. Ramachandran A, Mary S, Yamuna A, Murugesan N, Snehalatha C. High prevalence of diabetes and cardio-vascular risk factors associated with urbanization in India. Diabetes Care. 2008;31:893-898.

17. Upadhyay RP, Misra P, Chellaiyan VG, et al. Burden of diabetes mellitus and prediabetes in tribal population of India: a systematic review. Diabetes Res Clin Pract. 2013;102:1-7.

18. Zheng $\mathrm{Y}$, Lamoureux EL, Lavanya R, et al. Prevalence and risk factors of diabetic retinopathy in migrant Indians in an urbanized society in Asia: the Singapore Indian eye study. Ophthalmology. 2012;119(10):2119-2124. doi: 10.1016/j.ophtha.2012.04.027. Epub 2012 Jun 17.

19. Dierkx RI, van de Hoek W, Hoekstra JB, Erkelens DW. Smoking and diabetes mellitus. Neth J Med. 1996;48:150-162.

20. Beziaud F, Halimi JM, Lecomte P, Vol S, Tichet J. Cigarette smoking and diabetes mellitus. Diabetes Metab. 2004;30:161-166.

21. Wen CP, Cheng TY, Tsai SP, Hsu HL, Chan HT, Hsu CC. Exploring the relationships between diabetics and smoking with the development of glucose equivalent concept for diabetes management. Diabetes Res Clin Pract. 2006;73:70-76.

22. Kapoor D, Bhardwaj AK, Kumar D, Raina SK. Prevalence of diabetes mellitus and its risk factors among permanently settled tribal individuals in tribal and urban areas of in Northern state of Sub Himalayan region of India. 2014;2014:380597. doi: 10.1155/2014/380597. Epub 2014 May 6.

23. Moore WV, Fredrickson D, Brenner A, et al. Prevalence of hypertension in patients with type II diabetes in referral versus primary care clinics. J Diabetes Complications. 1998;12(6):302-306.

24. Kabakov E, Norymberg C, Osher E, et al. Prevalence of hypertension in type 2 diabetes mellitus: impact of the tightening definition of high blood pressure and association with confounding risk factors. J Cardiometab Syndr. 2006;1:95-101.

25. Joshi SR, Saboo B, Vadivale M, et al. Prevalence of diagnosed and undiagnosed diabetes and hypertension in India--results from the Screening India's Twin Epidemic (SITE) study. Diabetes Technol Ther. 2012;14:8-15.

26. Rodgers A, Lawes CMM, Gaziano T, Vos T. The growing burden of risk from high blood pressure, cholesterol and bodyweight. Diabetes: The Pandemic and potential solutions. In: Jamison DT, Breman JG, Measham AR, et al. (Eds). Disease Control Priorities in Developing Countries. 2nd ed. New York. USA. Oxford University Press; 2006. 